\title{
EVALUATION OF THE DYNAMIC AMPLIFICATION FACTOR FOR RAILWAY BRIDGES SUBJECTED TO A SERIES OF MOVING MASS
}

\author{
Mehrdad Bisadi ${ }^{1}$, Q.T. Ma $^{1}$ and S. Beskhyroun ${ }^{1}$ \\ ${ }^{1}$ Department of Civil and Environmental Engineering, The University of Auckland \\ 20 Symonds Street, Auckland 1010, New Zealand \\ mbis086@aucklanduni.ac.nz \\ \{q.ma, s.beskhyroun\}@auckland.ac.nz
}

Keywords: Railway Bridge, Finite Element, Dynamic Amplification Factor, Moving Mass Analysis.

\begin{abstract}
This paper investigates the vertical dynamic behavior of steel rail viaducts subjected to train passage. The analyses in this study take into account the dynamics of the vehicle suspension systems, the mass of bogies and car bodies, and the dynamic properties of the viaduct as emulated by idealized mass and stiffness values. The rail vehicles are simulated as a series of moving mass with various wheel distances traversing over simply supported girders. Using finite element software, LUSAS, the dynamic amplification factors are evaluated and the results are compared with standard design practice for a wide range of speeds and a range of viaduct spans. The results show that the impact factors proposed by design codes are unconservative in many cases especially for high speed trains traversing the short span viaducts.
\end{abstract}




\section{INTRODUCTION}

Research has shown modern high speed trains have the potential to induce resonance on railway bridges [1]. This phenomenon takes place when the frequency of excitation associated with moving train coincides with the natural frequencies of the bridge. Under such condition, the response of rail bridges is continuously amplified, as axle loads traverse over the bridge [2]. Excessive bridge response increases the likelihood of derailment, increase wheel and rail wear and may lead to the structural instability.

There exist two commonly used loading strategies to evaluate the dynamic response of the bridge-train system. These are known as the moving load and moving mass models. In a moving load model, the train is considered as a series of moving static axle loads and the inertial and dynamic effects of the suspension system are ignored. In a moving mass model, the train is simulated as a series of moving mass sprung systems that represents the wheels, bogies and coaches. This method is considered more realistic and leads to more accurate results when interactions are considered important [2,3]. Figure 1 shows a representative schematic of the models.

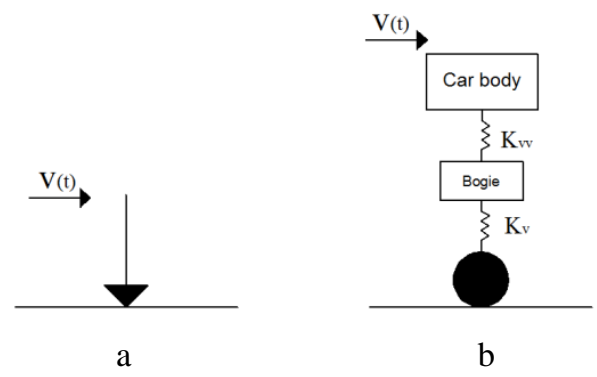

Figure 1: a) Moving load model b) Moving mass model

A number of researchers have developed sophisticated train models for evaluating the accurate dynamic response of railway bridges. Liu et al. developed a simple 3 degrees of freedom (DOF) train model to approximately investigate the properties of the train-bridge system [4]. While Xia et al. developed a 27 DOF train model to examine human comfort when a train traverse over a long suspension rail bridge [5]. In another study, Xia et al. developed an articulated train model to study the difference in bridge response from an articulated train compared to a non-articulated train passage [6]. Zhai et al. developed computer simulation software to predict vertical and lateral dynamic response of a train traversing a bridge and the results were validated by onsite experimental tests on two high speed railway bridges [7].

As far as rail bridge design is concerned, as opposed to pure analysis studies, most rail bridges worldwide are designed without a specific dynamic analysis. In this approach, a bridge system is analysed with a combination of axle loads in a static analysis. Then, the response is multiplied by a dynamic amplification factor, also known as an impact factor. This factor attempts to represent the increase in displacements and loadings due to dynamic effects [8,9]. However, as there is little known about the development of such factors, presumably they are based on limited empirical studies or moving loads approach, it is unsure whether it would accurately predict the dynamic effects of high speed moving loads.

The aim of this paper is to evaluate the vertical midspan dynamic amplification factor of steel railway bridges including the influences of varying axle distances, train suspension system, viaduct vertical natural frequencies and span lengths. The results are then compared with American railway bridges manual, AREMA, and Eurocode standard practice code $[10,11]$. 


\section{RESONANCE ON RAILWAY BRIDGES}

Dynamics of train-bridge systems are unique in that when trains traverse across a bridge, it increases the mass of the system significantly, trains represent a large portion of the mass in the system and make contact with bridges via a suspension system with individual dynamic characteristics. In simplistic terms, during train passage, the train bridge system can be approximately considered as a single system with the mass of the bridge and trains, resting on a structure with the stiffness of the bridge and is subjected to a dynamic load in accordance with the speed of the trains. The effect of the moving load can be considered as a single dynamic load with a forcing frequency depending upon train speeds, the axle wheel distances and span length of rail bridges. Higher train speed increases the forcing frequency and similarly shorter axle distance over spans also increase the effective forcing frequency. This frequency is expressed in equation 1 , where $\left(f_{c}\right),(V)$ and $\left(L_{b}\right)$ are the forcing frequency, train speed and the bridge span length respectively [2].

$$
f_{c}=\frac{V}{L_{b}}
$$

In moving load analyses, the dynamics of the train system are typically ignored. In moving mass analysis, an attempt is made to incorporate this effect by modelling the train as a dynamic system of the car bodies and bogies (train suspensions). This leads to a two DOF system and consequently the train is defined by two natural frequencies. Equation 2 and 3 estimate these two natural frequencies as a function of the primary and secondary suspension system spring stiffness $\left(k_{v}, k_{v v}\right)$ and mass of the bogie and car body $\left(m_{l}\right.$ and $\left.m_{2}\right)$ [4].

$$
\begin{gathered}
f_{v c}=\frac{1}{2 \pi} \sqrt{\frac{\frac{2}{\frac{1}{k_{v v}}+\frac{1}{2 k_{v}}}}{m_{2}}} \\
f_{v b}=\frac{1}{2 \pi} \sqrt{\frac{2 k_{v}+k_{v}}{m_{1}}}
\end{gathered}
$$

Dynamic characteristics of railway bridges also play a key role in train-bridge interaction problem. For this study, this is represented by the bending of a single simply supported bridge span. This leads to natural frequencies that are functions of bending stiffness $(E I)$, span length $\left(L_{b}\right)$ and mass of the bridge ( $m$ per unit length). Equation 4 shows the first vertical natural frequency of such a simply supported beam [12].

$$
\omega_{b}=\frac{\pi}{2} \sqrt{\frac{E I}{m L_{b}^{4}}}
$$

Research shows that amplified train-bridge response can be expected when the forcing frequency $\left(f_{c}\right)$ coincides with any of the natural frequencies mentioned above. The most critical of these pairing is when the forcing frequency coincides with a natural frequency of the bridge. Equation 5 estimates the train speeds when this occurs. As the bridge is in fact a continuous system, other critical speeds occur at integer multiple of Equation 5 corresponding to a compatible vertical bridge mode shape. $\left(L_{c}\right)$ denots the carriage length. $[2,13]$. 


$$
V=\frac{\omega_{b} L_{c}}{2 i}, \quad \mathrm{i}=1,2,3, \ldots
$$

\section{IMPACT FACTOR AND RELATED ISSUE}

Impact factors (I) or dynamic amplification factors simplify the rail bridge design process by approximately accounting for the train-bridge dynamic interaction by upscaling the results of a static analysis. Equation 6 presents the common definition for impact factor.

$$
I=\frac{\max \text { dynamic response }}{\text { max static response }}
$$

Various equations exist in different bridge design standards for dynamic amplification factors as a function of span lengths and different traffic load models [8]. For instance, AREMA assumes two traffic load models, cooper E80 and alternative loads on four axles with a value of 100,000 $\mathrm{lb}$ force per axle, leading to equation 7 for an expression for the dynamic amplification factor. It can be observed from this equation, AREMA considers span length as the only parameter affecting the dynamic interaction [10].

$$
\begin{array}{cc}
I=1.4-\frac{3 L_{b}^{2}}{14860} & \mathrm{~L}_{\mathrm{b}}<24 \text { feet } \\
I=1.16+\frac{1.829}{L_{b}-9.1} & \mathrm{~L}_{\mathrm{b}} \geq 24 \text { feet }
\end{array}
$$

Eurocode EN1991-2 assumes different loading models for their rail bridges design guidance. Naturally, the formulas for impact factors are different, but notably, the Eurocode formulas are functions of train speed, bridge natural frequency for the existing bridges and span length for new bridges. Equations 8 and 9 present the dynamic impact factor formulas for carefully and normally maintained tracks as they appear in the Eurocode. EN1991-2 also prescribes a more detailed dynamic analysis if the train speed is expected to exceed $200 \mathrm{~km} / \mathrm{hr}$ [11].

$$
\begin{aligned}
& I=\frac{1.44}{\sqrt{L_{b}}-0.2}+0.82 \\
& 1.00 \leq I \leq 1.67 \\
& I=\frac{2.16}{\sqrt{L_{b}}-0.2}+0.73 \\
& 1.00 \leq I \leq 2.00
\end{aligned}
$$

Equations 7 to 9 are plotted together in Figure 2. It highlights that AREMA is generally more conservative than the Eurocode particularly in longer span bridges. 


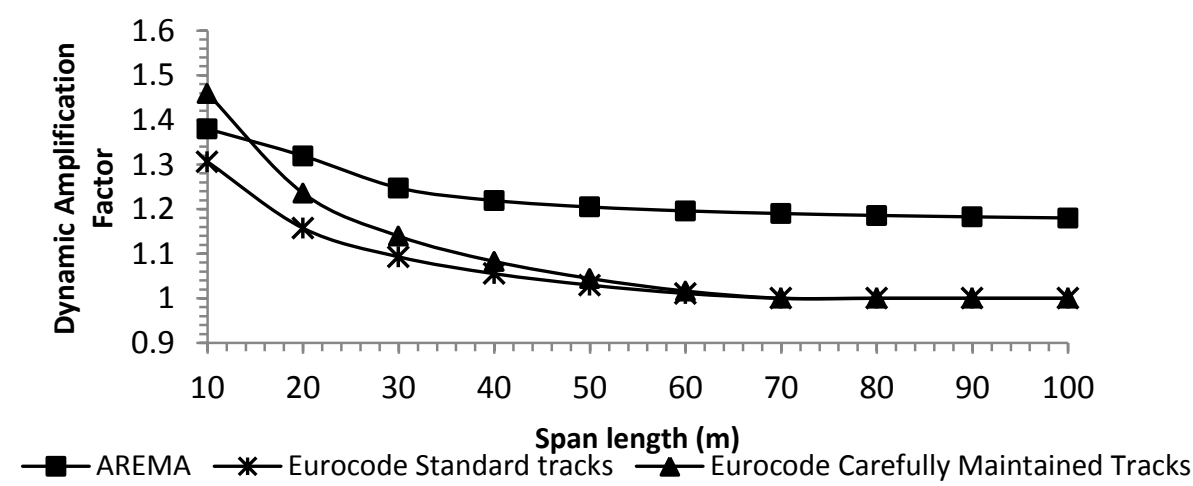

Figure 2: Comparison of dynamic amplification factor suggested by AREMA and Eurocod

\section{FINITE ELEMENT ANALYSIS}

\subsection{Finite element model}

Research has shown the vertical vibration and deflection are the most critical in studying the train bridge interaction and that a two dimensional model is sufficient in simulating study the vertical dynamic response [13]. This study employs a commercial finite element (FE) software, LUSAS (version 15.0.5) to create and analyse a two dimensional FE model of a train bridge system. The bridge is modelled as a linear elastic simply supported steel beam. The study considers a series of bridge span from 10 to $60 \mathrm{~m}$ and the mass of the bridge is set as $15 \mathrm{ton} / \mathrm{m}$.

The train is simulated as a sequence of rigid sprung masses traversing over the beam. Figure 3 shows a schematic of the FE model. Each sprung mass represents a quarter of the car body mass and half of the bogie mass for one train wagon.

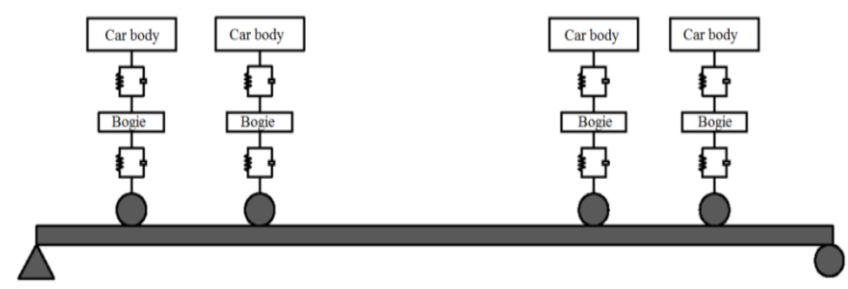

Figure 3: FE model of the interaction system

The simulated train consists of eight passenger cars and the length of each car is $25.5 \mathrm{~m}$. Table 1 shows the train parameters for this study. These parameters have been taken from a real train with minor modifications [14].

\begin{tabular}{lll} 
Item & Unit & Value \\
\hline Mass of car body & Ton & 42 \\
Mass of bogie & Ton & 3 \\
Mass of wheel & Ton & 1.8 \\
Vertical stiffness of primary suspension system & $\mathrm{kN} / \mathrm{m}$ & 210552 \\
Vertical stiffness of secondary suspension system & $\mathrm{kN} / \mathrm{m}$ & 26319 \\
Vertical damping of primary suspension system & $\mathrm{kN} \mathrm{s} / \mathrm{m}$ & 15250 \\
Vertical damping of secondary suspension system & $\mathrm{kN} \mathrm{s} / \mathrm{m}$ & 18125 \\
\hline
\end{tabular}

Table 1: Train dynamic characteristics. 


\subsection{Dynamic analysis}

Modal superposition method is employed to analyse the FE model. The following assumptions are adopted:

- The materials behave linearly;

- Train moves with constant speeds;

- The spring and dashpots behave linearly.

- Modal damping coefficient is assumed to be 5\%, and

- There is no separation between the wheels and the bridge.

A unit load is defined to produce small discrete locations over the path of train, by setting up a number of load cases. An eigenvalue analysis is carried out to compute the natural frequencies and eigenvectors of the bridge. Using the discrete unit load and the eigenvectors, modal forces are computed and then modal superposition method is applied to solve the interaction problem. Newmark time integration method is used and the dynamic responses of the train and the bridge are computed. To increase the accuracy of results, mass participation factors are considered over $90 \%$, the discrete locations $(\delta)$ produced by the unit load is considered sufficient small and a proper time incerment $\left(\Delta_{\mathrm{t}}\right)$ is used for the time integration method. The time step is computed according to equation 10 proposed by Clough and Penzien [15]. The distance incerment value is calculated by equation 11 suggested by LUSAS user manual [16].

$$
\begin{gathered}
\Delta_{t}=\frac{\omega_{\max }}{10} \\
\delta=10 \times \frac{1}{2 \times \omega_{\max }}
\end{gathered}
$$

\subsection{Verification of the finite element model}

Yang et al [2] has considered a bridge as a beam and train as a moving mass and used the analytical method, mentioned in section 4 , to calculate the bridge dynamic response. The specifications of the system are as follows; Span length $L_{b}=25 \mathrm{~m}$, Train speed $V=27.78 \mathrm{~m} / \mathrm{s}$, Young's module $E=2.87 \mathrm{kN} / \mathrm{m}^{2}$, Poisson's ratio $v=0.2$, moment inertia $I=2.9 \mathrm{~m}^{4}$, mass of the bridge $m=2.303 \mathrm{ton} / \mathrm{m}$, mass of the bogie $M_{l}=5.75$ ton and spring rate $K_{v}=1595 \mathrm{kN} / \mathrm{m}$. Mass of the wheel and the damping rate are neglected.

For verification of the FE model, dynamic analysis for the bridge has been carried out in LUSAS environment. Figure 5 and 6 show that there is a good agreement between the LUSAS results and the results from reference [2].

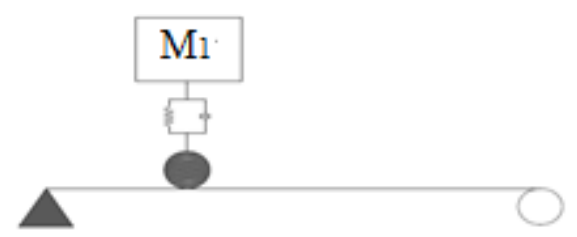

Figure 4: Simply supported beam subjected to a moving mass (Source: Reference [2]) 


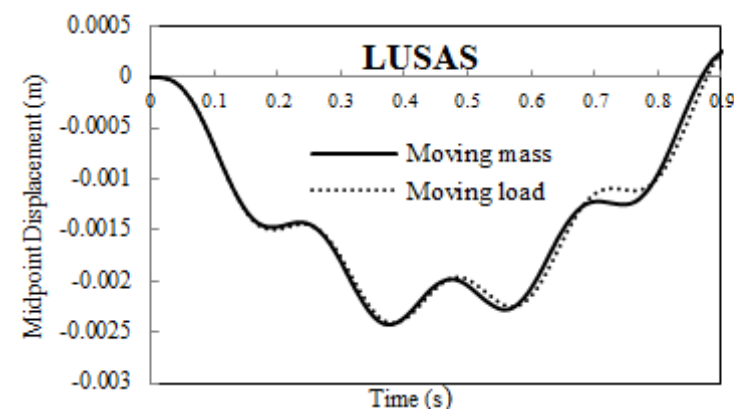

(a)

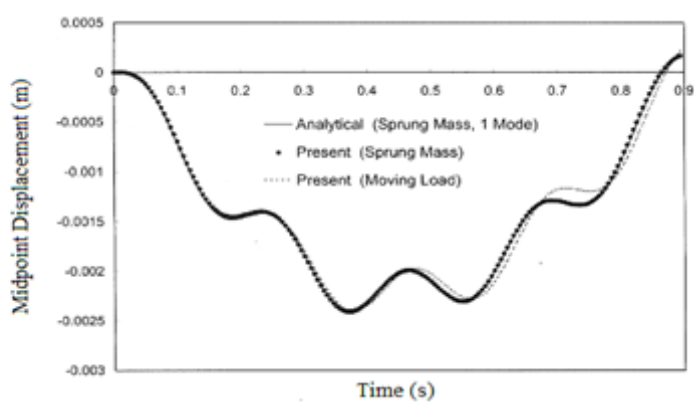

(b)

Figure 5: Beam midpoint vertical displacement a) FE model b) Numerical analysis (Source: Reference [2])

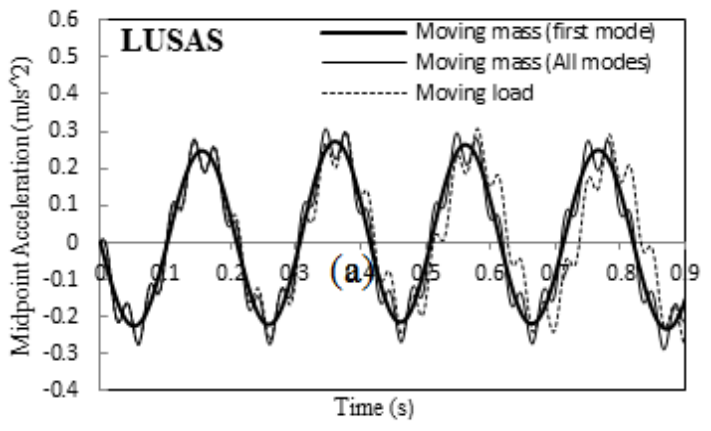

(a)

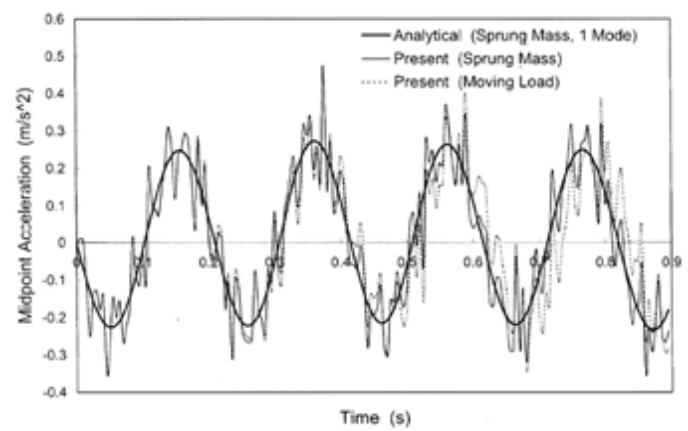

(b)

Figure 6: Beam midpoint vertical acceleration a) FE model b) Numerical analysis (Source: Reference [2])

\section{PARAMETRIC STUDY}

\subsection{Effect of rail vehicle suspension system}

To evaluate the effect of the vehicle suspension system on the interaction model, three different stiffness values for the suspension are assumed. Table 2 shows the spring rates. Each of the vehicles in the table 2 crosses the bridge with speed range from 50 to $300 \mathrm{~km} / \mathrm{h}$. To take the dynamic bridge properties into the account, a non-dimensional parameter $(S)$ as a function of Train speed $(V)$, the bridge natural frequency $\left(\omega_{b}\right)$ and the span length $\left(L_{b}\right)$ is defined. Equation 12 shows the non-dimensional parameter. The bridge dynamic amplification factors and bogie accelerations are computed and illustrated in figures 7 and 8 .

\begin{tabular}{ccccc} 
Train & \multicolumn{2}{c}{ Spring rate $(\mathrm{kN} / \mathrm{m})$} & \multicolumn{2}{c}{ Damping rate $(\mathrm{kN} \mathrm{s} / \mathrm{m})$} \\
\hline Type & Primary & Secondary & Primary & Secondary \\
Vehicle1 & 1177 & 132.5 & 511 & 606.5 \\
Vehicle2 & 11800 & 2650 & 511 & 606.5 \\
Vehicle3 & 30000 & 6000 & 511 & 606.5 \\
\hline
\end{tabular}

Table 2: Characteristics of train suspension system

$$
S=\frac{V}{\omega_{b} L_{b}}
$$




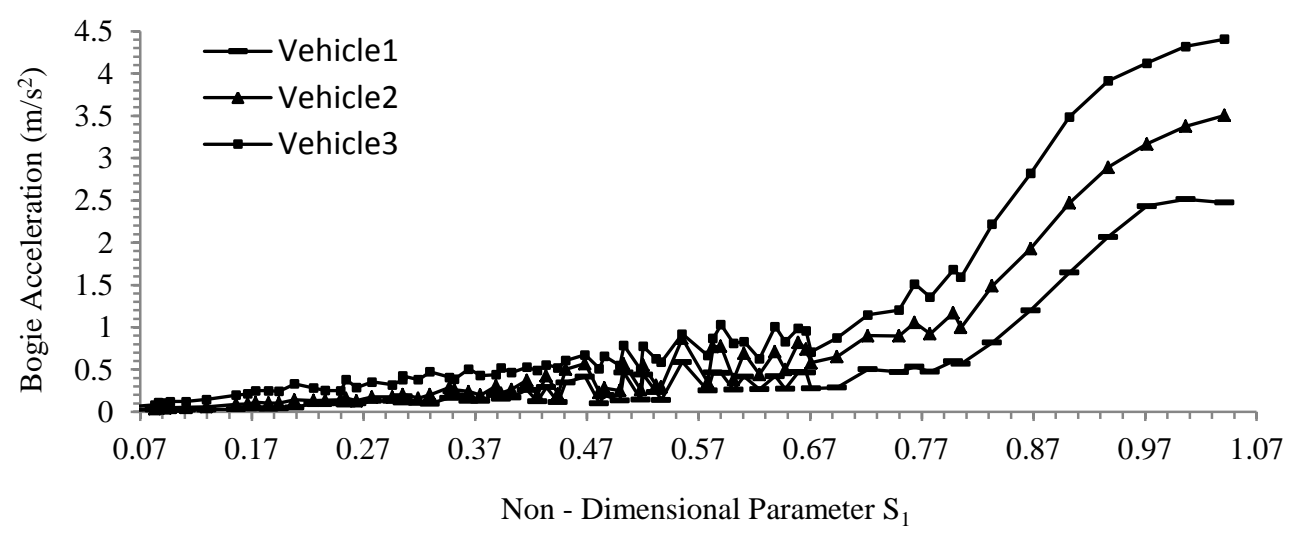

Figure 7: Vertical train bogie acceleration

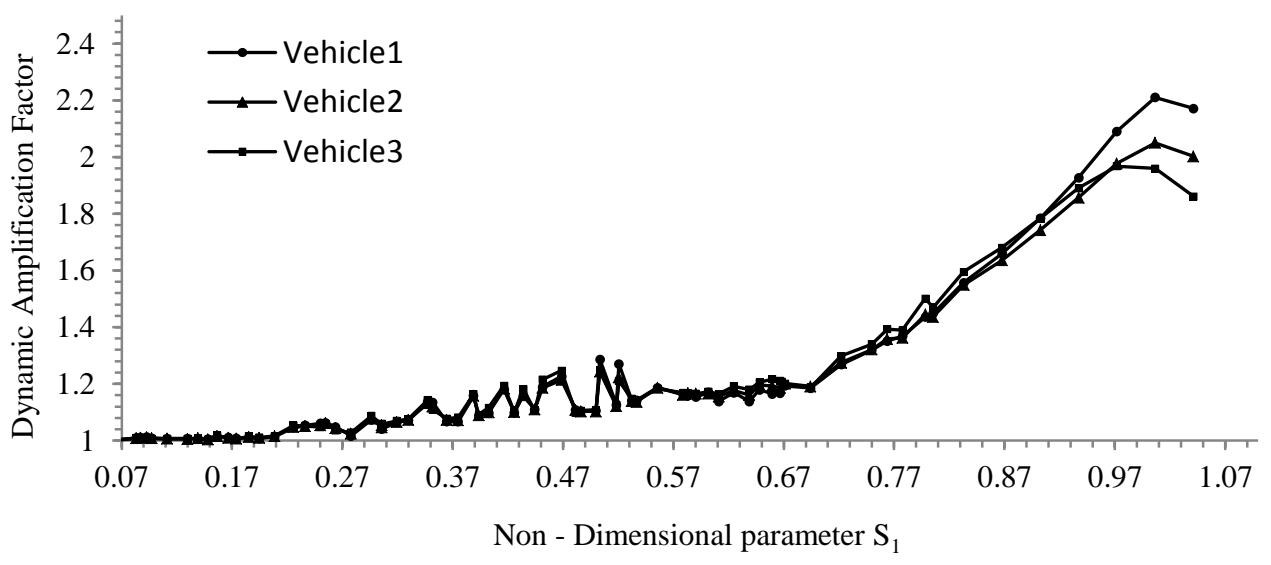

Figure 8: Vertical midpoint bridge dynamic amplification factor

It can be seen that the stiffer springs increase the vertical bogie accelerations. The main reason is that the higher spring rates increase the frequency of the sprung mass which may approach to that of the bridge and increase the risk of resonance. The high train frequency assuredly leads to passenger discomfort. On the other hand, the stiffer springs slightly reduce the response of the beam. As the reduction is small, the effect of that is negligible in the bridge design procedure. Some of the standard design codes propose stability indices for maximum train acceleration. This value in China standard code is $1.3 \mathrm{~m} / \mathrm{s}^{2}$ [14].

\subsection{Effect of rail bridge characteristics}

To evaluate the bridge dynamic amplification factor, various span lengths are considered for the bridge and four different values of the frequency are allocated to each span length. Table 3 shows the bridge specifications. The train with axle distances $14 \mathrm{~m}, 18 \mathrm{~m}$ and $21 \mathrm{~m}$ crosses each of the bridges. In total 72 analyses are carried out for the train speed range from 50 to $300 \mathrm{~km} / \mathrm{h}$. The dynamic amplification factors at the midpoint of the bridge are computed and illustrated in figure 9. 


\begin{tabular}{ccc} 
Span length $(\mathrm{m})$ & $\begin{array}{c}\text { First vertical natural } \\
\text { frequency }(\mathrm{Hz})\end{array}$ & Damping ratio \\
\hline $10-20-30-40-50-60$ & $3-4-5-6$ & $5 \%$ \\
\hline
\end{tabular}

Table 3: Physical parameters of beam.
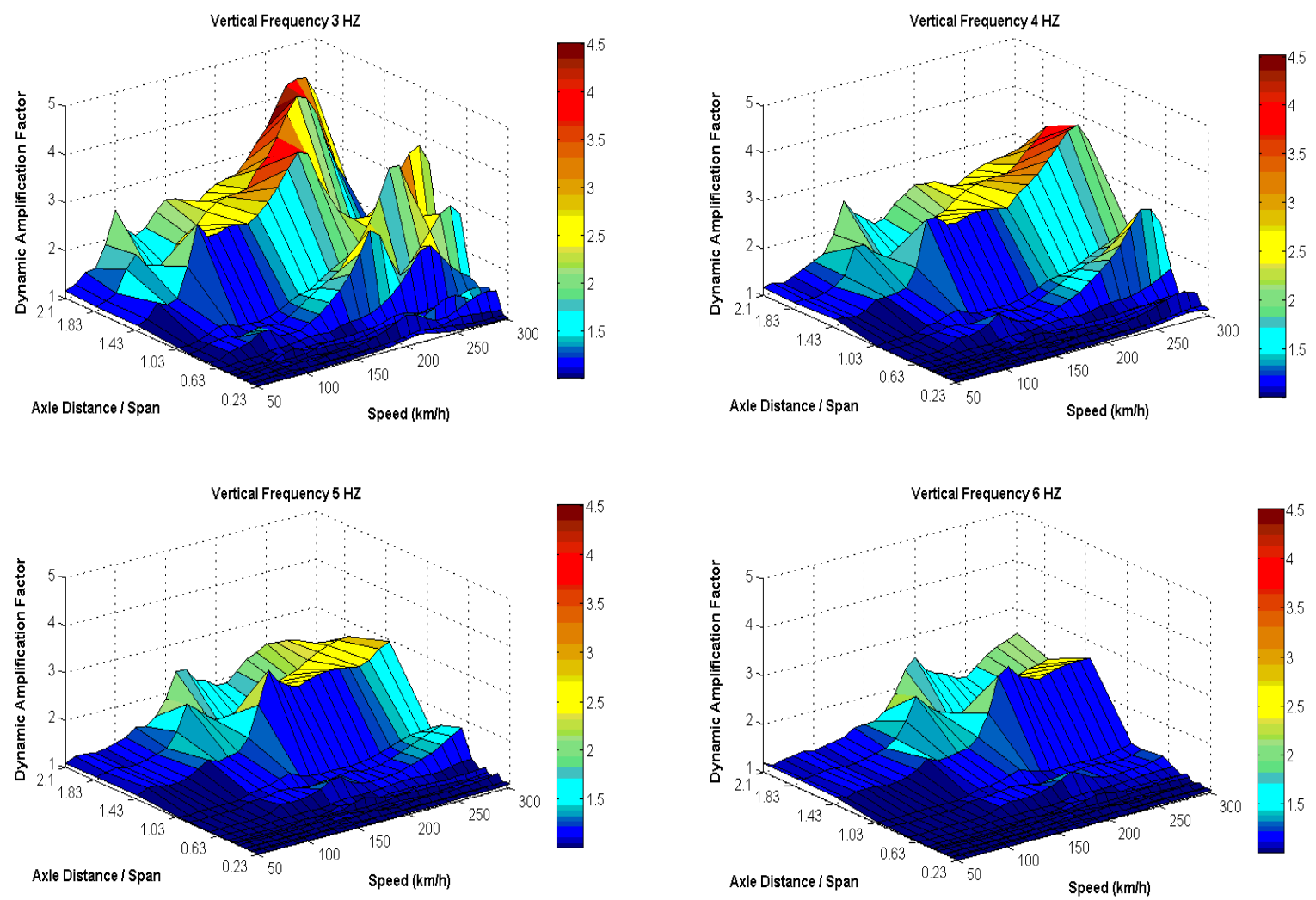

Figure 9: Midpoint vertical dynamic amplification factor of the bridges

Figure 9 shows the effects of train speeds, axle distances, bridges frequencies and span lengths on the dynamic amplification factor. Due to the resonance phenomenon, the dynamic amplification factors shift to larger values in response to higher train speeds, shorter span lengths and larger axle distances. The bridges with lower frequencies also experience higher dynamic responses. In comparison with the design codes, AREMA and Eurocode respectively suggest 1.4 and 2 as the maximum values for the dynamic amplification factors. However, the obtained values are much larger when the train with higher speeds traverses over the bridge with shorter span length.

\section{CONCLUSION}

A parametric study was carried out to investigate the effect of various parameters on the dynamic response of a train bridge system. The parameters include train speed, bridge natural frequency, span length, axle distance and train suspension system. The following conclusion has been drawn from this study: 
- Stiffer suspension system results in larger values of bogie acceleration. However, it has a negligibale influence on the bridge response.

- The bridge dynamic amplification factors increase when train crosses the bridge with higher speeds. This response is more apparent in short span lengths, larger axle distances and lower bridge natural frequencies.

- Comparing the results with AREMA and Eurocode, it can be seen that the proposed impact factors are underestimate.

\section{REFERENCES}

[1] R. Delgado, R. Calçada, D. Riberio, J.R. Pinto, H. Figueiredo, Assessment of the dynamic response of high speed railway bridges in interoperable lines. R. Delgado, R. Calçada Boca, J.M. Goicolea, F. Gabaldon. Dynamics of High-Speed Railway Bridges, London, 2009.

[2] Y.B. Yang, J.D. Yau, Y.S. Wu, Vehicle-bridge interaction dynamics with applications to high-speed railways. World Scientific 2004.

[3] C. Rigueiro, C. Rebelo, L.S.d. Silva, Influence of ballast models in the dynamic response of railway viaducts. Journal of Sound and Vibration, 329, 3030-3040, 2010.

[4] K. Liu, G.D. Roeck, G. Lombaert, The effect of dynamic train-bridge interaction on the bridge response during a train passage. Journal of Sound and Vibration. 325, 240-251, 2009.

[5] H. Xia, Y.L. Xu, T.H.T. Chan. Dynamic interaction of long suspension bridges with running trains. Journal of Sound and Vibration, 237, 263-280, 2000.

[6] H. Xia, N. Zhang, G. D. Roeck, Dynamic analysis of high speed railway bridge under articulated trains. Computer and Structures. 81, 2467-2478, 2003.

[7] W. Zhaia, S. Wanga, N. Zhang, M. Gao, H. Xia, C. Cai, C. Zhao, High-speed train-trackbridge dynamic interactions - Part II: experimental validation and engineering application. International Journal of Rail Transportation.1, 25-41, 2013.

[8] S.A Hamidi, F. Danshjoo, Determination of impact factor for steel railway bridges considering simultaneous effects of vehicle speed and axle distance to span length ratio, Engineering Structures. 32, 1369-1376, 2010.

[9] J.F. Unsworth, Design of modern steel railway bridges. Taylor and Francis, 2010.

[10] American Railway Engineering and Maintenance-of-Way Association Manual. 2014.

[11] Designer's guide to Eurocode 1: actions on bridges, EN 1991-2, EN 1991-1-1, -1-3 to -17 and EN 1990 Annex A2. Thomas Telford 2010.

[12] A.K. Chopra, Dynamics of structures: theory and applications to earthquake engineering, 4th Edition. Prentice Hall, 2012. 
[13] M. Sogabe, N. Matsumoto, M. Kanamori, T. Sato, H. Wakui. Impact factors of concrete girders coping with train speed-up. Quarterly Report of Rail Technical Research Institute. 1, 46-52, 2005.

[14] N. Zhang, H. Xia, W. Guo, Vehicle-bridge interaction analysis under high-speed trains. Journal of Sound and Vibration. 309,407-425, 2008.

[15] R. Clough, J. Penzien. Dynamic of structures. McGraw Hill, New York 1975.

[16] Lusas finite element user manual, Version 15-0-5, finite element analysis Ltd, UK. 